\title{
Radiosensitivity Index
}

National Cancer Institute

\section{Source}

National Cancer Institute. Radiosensitivity Index. NCI Thesaurus. Code C114480.

A set of genetic markers that predicts the fraction of cells that could survive radiotherapy based on the expression levels of 10 genes (AR, JUN, STAT1, PKC, RELA, ABL, SUMO1, CDK1, HDAC1, and IRF1) in a patient's tumor. 